\title{
Unaccusativity in Embosi
}

\author{
Yvon Pierre Ndongo Ibara \\ Maître de Conférences CAMES
}

\begin{abstract}
My research explores one of the intransitive predicates called unaccusatives driving data from Embosi, a Bantu language. It comes out further to discussion that unaccusative predicates are semantically driven since syntax utilizes semantic information of these predicates. This study confirms that passivization, causative alternation, and resultative constructions are among the key tests regarding unaccusativity. Most unaccusative predicates are cross linguistically based, what distinguishes them from one language to one another is the language morphological productivity. In fact, Embosi shows that unaccusative properties are inherent to the verb itself, but not to the verb phrase.
\end{abstract}

Keywords: Unaccusativity, Embosi, intransitive predicates, syntax, semantics, morphology.

\section{INTRODUCTION}

The main objective of this work is to analyse the ways Embosi realises Split Intransitivity Hypothesis.According to the literature available, (Hall 1965, Perlmutter 1978, Belleti and Rizzi 1981, Burzio 1986, Grewendorf 1989, Radford 2009) intransitive predicates are divided into two classes notably unergatives and unaccusatives. In what follows, we will be discussing the properties, the structure and the idiosyncratic features of unaccusative predicates in Embosi. The question this study addresses are the following:

(1) Are unaccusative predicate tests cross linguistically based?

(2) Are predicates belonging to unaccusative predicate class cross linguistically based or part of language idiosyncrasy?

(3) What are Embosi tests to depict unaccusative predicates?

(4) Are there any language universal governing unaccusativity?

This paper includes four sections. Section 1 provides an overview of unaccusativity properties. The syntax semantic interface in terms of structure of unaccusatives is the concern of section 2. In section 3, I discussed well-known unaccusativity tests based on English to avoid melting different arguments. Finally, section 4 deals unaccusative analysis in Embosi language.

\section{UnacCuSativity Properties}

Unaccusative predicates are part of the traditional intransitive verb class which appears with one argument. Thanks to works by Perlmutter's (1978) seminal work, it has been demonstrated that the unique argument of intransitive verbs has different underlying positions; hence Unaccusative Hypothesis has been put forward. In this connection, unaccusative predicate subjects are semantically theme or patient, this is to say that, they are post verbal at the logical form position. In the ensuing lines, our attention is drawn on the different predicates that meet unaccusative condition.

Firstly, the following examples concern the many different predicates that instance unaccusativity features, consider:

(1) a. The river has frozen

b. There could have occurred a diplomatic incident (Radford, 2009, 249)

c. The day began well

d. There does still remain some hope of finding survivors (Radford, 2009, 249) 


\section{e. The sun is shining.}

f. The car swung right round.

g. We arrived at the station.

In all the sentences in (1) above, the predicates select only one argument. But at semantic level, the predicates subcategorize arguments which are devoid of agentivity. In this respect, the grammatical argument occurring in front of the verbs do not do something which is expressed by the verb.

Following the same line of evidence, we argued that unaccusative predicates are intimately compatible with the expression of telic events. As things stand, unaccusative predicates denote actions that havea natural end point. Furthermore, the argument of unaccusative predicates do have not the control of the event

In addition to telicity, unaccusatives are of two main classes, that is, prototypical and derived unaccusative predicates. The former refers to unaccusatives which have properties denoting existence or appearance whereas the latter is about unaccusative verbs that express a change of state as illustrated below.

(2) a. Lots of roses grewin the garden.

b. The bombs burst.

c. The river has frozen.

d. My heart melt.

The distinction between prototypical and derived unaccusatives will be necessary when dealing with the different tests about unaccusativity.

\section{UNACCUSATIVEPREDICATE STRUCTURE}

This section is about the derivation and representation of unaccusative predicates based on generative framework. To begin, unaccusative verbs fall into the heterogeneous class of intransitives which are classified as one-place-predicate. The specificity of unaccusatives lies on the fact they select internal NP. To quote Radford -op. cit.) "The overall conclusion to be drawn from the discussion so far is that subjects originate internally within VP, as theta-marked arguments of the verb." Then thanks to Huang (1982) Constraint on Extraction Domain which stipulates that only complement positions are the best root position from where sentence materials can be taken together with Extended Projection Principle, the empty subject position will be filled by the verb complement as shown in:

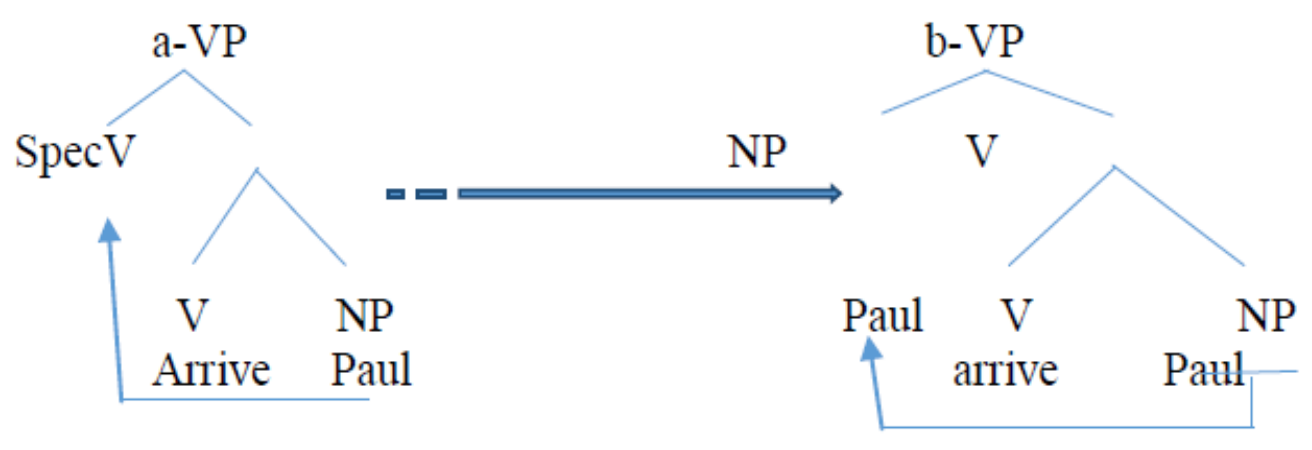

The P-marker (3a) represents the basic position of the unique argument of the verb. It shows that this argument has object-property and semantically it is a Theme. But the tree diagram in (3b) is about the position of the internal argument at the Phonetic Form.

In addition, based on Burzio's Generalization which assumes that a verb which does not have an external argument does not assign accusative case. This can be summarized as follows:

a. Only verbs, which assign external $\Theta-$-role, assign accusative Case (Burzio 1986: 178)

b. A verb, which fails to assign accusative Case to its object, does not assign an external $\Theta$-role (Burzio 1986: 184). 
Yet it is important based on Chomsky (1986a) to highlight that the case is twofold, that is, inherent and structural case. In this connection, Motsa Zwakele (2006:28) assumes that "inherent Case as the type of Case assigned at D-structure. It is associated with 8-marking i.e. a head assigns inherent Case to a DP it $\Theta$-marks. Inherent Cases are genitive Case and dative Case".

In addition, structural case is explained in the following lines.

- In contrast, structural Cases are nominative and accusative: they are not assigned to DPs according to their 8-roles, but at S-Structure according to the structural position of the DP. Verbs, prepositions and [+ finite] I assign structural Cases to DPs. (Motsa Zwakele ibid)

In the light of the above argument, unaccusative verbs are devoid of ability to assign any case since they lack external argument. In the upcoming sections, we are going to deal with different tests used to testify whether a verb is unaccusative or not. Because unaccusative predicate is part of language parameters that differ languages cross linguistically; our attention will be focused on English languages.

\section{UnACCUSATIVE TeStS}

This section provides a body of evidence for depicting an unaccusative predicates driving data from English as in:

(4) a. Mistress Page is come with me (Mrs. Ford, Merry Wives of Windsor, V.v) 2009:252)

(Radford,

b. There arrived a message in my inbox.

*c. There melted a lot of snow.

d. John painted the car green.

e. A fallen soldier.

f. Leave you now (Radford, 2009:251)

*g. Read you that book (Radford, 2009:252)

h. In the distance appeared the towers and spires of a town (Levinand Rappaport Hovav1995:218)

Unaccusatives have a number of properties that can be checked through a number syntactic operations. There are three syntactic diagnostic tests that have been put forward by Burzio (1986) among which the selection of an auxiliary. In English, the unaccusative verbs select the auxiliary be as their perfect auxiliary as shown in (4a). This is also attested in Italian (Burzio 1986:53) and French (Harves 2002:23). In addition to the auxiliary selection, the unaccusative predicates in English allow an expletive subject (there) to appear at the Spec of TP as in (4b). Yet, not all unaccusatives can select There as their subject as in (4c). The oddness of (4c) is due to the fact that unaccusatives have two classes with different semantic properties. As a matter of fact, some unaccusative verbs express the idea of appearance or existence whereas others denote a definite change of state. The former refers to (4b) whilst the latter to (4c). Putting things slightly in the same way, I argue that only unaccusatives with existence and appearance feature can select There as a subject, while those about define change cannot select There as their subject, hence justifying the ungrammaticality of (4c). The third argument in connection to unaccusative tests in English is about resultative construction. According to Levinand Rappaport Hovav(1995:34) a resultative construction is defined as "a phrase that denotes the state achieved by the referent of the DP, it is predicated of as a result of the action denoted by the verb in the resultative construction." As things stand, the resultative construction implies an NP which is naturally the object of the predicate. In fact, this construction obeys the Direct Object Restriction which stipulates that only direct object can well represent entity that undergoes the verb action since the direct object are predicated post-verbally and receive Theme or Patient role (Van Valin 1990). As unaccusatives are telic predicates, they are undoubtedly the best candidate for resultative construction. A further argument concerns the past participle of unaccusative verbs. It has been widely developed in the literature (Borgonovo et Cummins 1998, Levin 1993, Hoekstra 1984, Ackema 1995, to quote but a few) that the past participle of unaccusatives can appear as an internal modifier within an NP since it has adjectival value. To see how it works consider (4e). Furthermore, Henry (1995) argues that in the English variety spoken in Belfast, unaccusative predicates can have post-verbal subjects; (4f) is an illustration. The oddness of $(4 \mathrm{~g})$ can be accounted of by the fact that this verb is not an unaccusative. 
Finally, unaccusative predicates can also be tested through locative inversion construction. to quote Zwakele (2006:59)

- It is assumed that only intransitive verbs can be found in locative inversion constructions, and notably not all intransitive verbs, but only unaccusative verbs and passive verbs are allowed to form locative inversion constructions.

Locative inversion construction is possible with unaccusative predicates because their subject position is empty at underlying position. As things stand, if only the predicate subject position is filled an overt DP, locative inversion construction will not be possible because the Spec, TP position will surface with two independent and unrelated subjects.

We can formulate the hypothesis according to which there are six tests capable of diagnosing English unaccusative predicates as aforementioned. Therefore, it is worth mentioning that unaccusativity hypothesis is also attested in Embosi. The following lines are devoted to the study and analysis of unaccusative predicates in Embosi. In these lines, we raise the question whether the tests discussed above or other tests exist in Embosi or whether predicates having the semantic properties can share similarities cross linguistically.

\section{UNACCUSATIVE IN EMBOSI}

The objective of this section is to show the different tests Embosi language allows in connection to Unaccusativity hypothesis.

\subsection{Passivization}

Our analysis of passivization follows Baker (1988), Chomsky (1999), and Radford (2009). It comes out from their works that the passive predicates have properties that are akin with unaccusativity hypothesis. In this respect, the fact that the DP c-commanded by the verb is anteposed owing to passivization process, that verb fails to assign nominative case to its external DP which receives case through the auxiliary. Examples (5) stand as the starting point.

(5)

\begin{tabular}{|c|c|c|c|c|c|}
\hline a- $\quad$ pó & $\mathrm{e}$ & si & $\beta s^{\prime}$ & M & ̀̀ \\
\hline Palaver & AGR & Already & tell & PASS & $\mathrm{FV}$ \\
\hline
\end{tabular}

\begin{tabular}{|l|l|l|l|l|l|l|}
\hline b- olangi & o & bondz & im & I & la & koli \\
\hline Bottle & AGR & Break & PASS & FV & at & night \\
\hline \multicolumn{7}{|c|}{ A bottle was broken at night } \\
\hline
\end{tabular}

\begin{tabular}{|l|l|l|l|l|l|l|}
\hline c- bwanga & o & bin & im & I & o & mboa \\
\hline Dance & AGR & dance & PASS & FV & at & village \\
\hline \multicolumn{8}{|c|}{ A dance was performed at the village } \\
\hline
\end{tabular}

\begin{tabular}{|l|l|l|l|l|l|l|l|l|}
\hline d- ndai & e & sz & aa & E & tong & im & a & $\beta$ a \\
\hline House & AGR & AUX & FV & AGR & build & PASS & FV & here \\
\hline \multicolumn{8}{|c|}{ A house was built here } \\
\hline
\end{tabular}

\begin{tabular}{|l|l|l|l|l|l|l|l|l|}
\hline e- olangi & o & bondz & im & i & la & nga & La & koli \\
\hline Bottle & AGR & break & PASS & FV & by & me & At & night \\
\hline \multicolumn{7}{|c|}{ A bottle was broken by me at night } \\
\hline
\end{tabular}

In the light of examples (5), it appears that the Embosi passive morpheme is '-m'. It is assumed that the passive morpheme is the external argument, hence it occupies a position higher than a VP.So, when deriving a passive construction, Embosi speakers have either the choice to omit the agent DP of the transitive counter forms as in (5a-d) or to realize it as a complement of a PP as illustrated in (5e). In both cases, the DP in the Spec, TP is predicated as the object of the verb. Moreover, the passive construction can also imply the passive morpheme and the auxiliary. The agreement distribution is twofold therefore. This means that when there only appears a predicate with a passive morpheme incorporated, the agreement marker is prefixed to the verb (5a-c, 5f), whilst once there occurs an auxiliary and a predicate with a passive morpheme attached, the agreement marker is reduplicated both with the predicate and the auxiliary as in $(5 \mathrm{~d})$. 
Since the external position of predicate is already filled by an overt argument, having another argument in the same position will violate Theta Criterion which postulates that an argument is assigned a theta role only once. Zwakele (2006:69) explains this process as follows:

- Thehypothesis is that the passive morpheme is an external argumentof the verb and that explains why there cannot be an external argument DP in a passive: having both the passive morpheme and an external agent DP would violate the Theta Criterion, which states that each theta-role is assigned to one and only one argument.

The P-maker below shows the different Move steps that are involved when deriving a passive construction in Embosi.

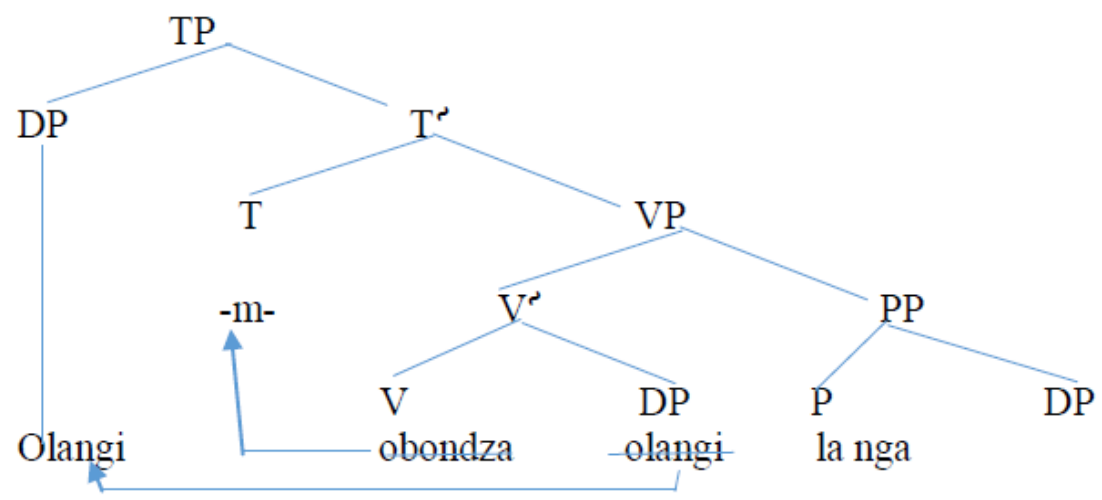

The movement of either the predicate or the DP is motivated by Attract Closest Principle which reads as " $A$ head which attracts a given kind of constituent attracts the closest constituent of the relevant kind" (Radford, op.cit:216) which is itself constrained by Locality Principle which postulates that "Grammatical operations are local" (Radford, op.cit: 21) and we can conclude with Preposing condition which states that "When material is preposed in order to highlight it, what is preposed is the smallest possible maximal projection containing the highlighted material." (Radford, op.cit: 66). Under the three conditions, the issue that is raised is that Move aims to enable word merging in order to help them check their features for the grammaticality of the sentence. The movement of the internal and post verbal DP to the Spec, TP position is the consequence of case-driven A movement. In other words, once transitive predicates get passivized, they are hence devoid of the capacity to assign accusative case. As an immediate consequence, their subject position is then empty. Because the empty subject position is found in a locality wherein a DP is located right hand, this DP will be attracted to the Spec, TP position as being locally attached and fulfilling the conditions of a subject. However, the movement of the verb from the head position of VP to T is morphologically based. This process is referred to the Stray Affix Filter (Baker 1988). According to this principle which looks like Chomsky Affix Hoping Principle, an affix is attached to the predicate at the Phonetic Form. This looks like a covert movement. As things stand, we can hypothesize that passive constructions in Embosi are instances of unaccusatives derived from transitive through passivization rule.

(6)

\begin{tabular}{|l|l|l|l|l|}
\hline a- olangi & o & bondz & i & Nga \\
\hline bottle & AGR & break & FV & Me \\
\hline \multicolumn{4}{|c|}{ breaker } \\
\hline \multicolumn{2}{|l|}{ A bottle was broken by me } & \\
\hline
\end{tabular}

\begin{tabular}{|c|c|c|c|c|}
\hline \multirow{3}{*}{$\begin{array}{l}\text { b- } \quad \text { bwanga } \\
\text { dance }\end{array}$} & ye & bin & $a$ & Ngala \\
\hline & AGR & dance & FV & Ngala \\
\hline & which & Dance & & \\
\hline
\end{tabular}

\begin{tabular}{|l|l|l|l|l|l|l|l|}
\hline c- ndai & e & dz & aa & E & tong & à & Ngùnda \\
\hline house & AGR & AUX & FV & AGR & build & FV & Ngunda \\
\hline \multicolumn{2}{|l|}{ A house was built by Ngunda } \\
\hline
\end{tabular}




\begin{tabular}{|l|l|l|l|l|}
\hline d- olangi & e & bondz & i & Nga \\
\hline Bottle & AGR & break & FV & Me \\
\hline \multicolumn{2}{|l}{} \\
\hline A bottle was broken by me & It & Break \\
\hline
\end{tabular}

In addition to the passive constructions illustrated in the examples (5) above, Embosi speakers provide another series of constructions with passive value as shown in (6). The question that immediately crops out concerns the identity of these sentences. Putting things quite similarly, we want to know if these sentences can be considered as passive construction. To answer this question, we should consider passivization properties. In this connection, Tallerman (2011:294) defines passive as

- A construction which changes the GRAMMATICAL RELATIONS of CORE ARGUMENTS in the following way: the original subject of an active sentence is demoted or deleted, and the object of the verb is promoted to the GRAMMATICAL RELATION of subject. The valency of a transitive verb is reduced, since it now contains a subject but no object. The change in grammatical relations is marked by changes to the verbal morphology.

It appears that passivization is characterized by:

- Applies to a transitive clause (the active clause) and forms an intransitive clause.

- Object promoted > subject.

- Former subject demoted > oblique argument, or is deleted; removed from the core.

- Changes occur in the morphology of the verb to signal passivization. (Tallerman, op.cit, 213)

When we try to compare examples (6) with passivization properties put forward by Tallerman (2011), we can conclude that these examples are illustrations of passive constructions because the demotion and promotion and the verbal morphology undergo changes. Yet it is at the morphological level that occurs some controversies.

The first observation one can make between the examples (5) and (6) lies on the presence and absence of the passive morpheme. All the predicates in (6) appear without the passive morpheme. As a matter of fact, does passivization always necessitate a morpheme at surface structure? It is generally assumed that the passive morpheme stands for the external argument. Since it is not incorporated to the predicate in the passive construction, we can admit that the verb morphology does not help know about the status of the external argument.

The second argument in support of some differences between (5) and (6) comes from the categorical change. In fact, if anti passivization makes a transitive verb detransitivized, Embosi language shows a case of nominalization of the predicate as in (6a). This means that Embosi speakers change the predicate into a noun while processing a passive construction, hence leading to a nominal sentence. This sentence has only nouns, but the information flow can be captured out by the argument hierarchy which looks like Theme/Patient $>$ Deverbal Noun> Agent.Our choice of deverbal noun instead of a thematic role is due to the fact that the derived noun has no semantic role, it only indicates a nounformed from a verb. In addition, the fact this derived noun does not undertake any movement proves it is in a position where it can get a thematic role.

Another argument comes from the Agreement feature between the external argument and the predicate. In example (5), it is obvious that the external argument control the agreement with its closest predicate, but in $(6 \mathrm{~b}, 6 \mathrm{c}, 6 \mathrm{~d})$ the external arguments do not have the control on the predicate. At semantic basis, this means that the external argument is not an agent, hence it cannot control agreement. This indeed confirms that the external argument isbased generated, that is, post verbal DPs.

The example (7) are concerned with another kind of passive construction in Embosi language.

(7)

\begin{tabular}{|l|l|l|l|l|}
\hline a- - langi & ba & bondz & A & wó \\
\hline bottle & AGR & break & FV & There \\
\hline A bottle is broken there \\
\hline
\end{tabular}

\begin{tabular}{|l|l|l|l|l|}
\hline b- $\quad$ ndai & ba & tong & A & pàà \\
\hline bottle & AGR & break & FV & Today \\
\hline A house will be built today \\
\hline
\end{tabular}




\begin{tabular}{|l|l|l|l|l|}
\hline e- $\quad$ bwanga & ba & bin & A & yàànà \\
\hline dance & AGR & dance & FV & day after tomorrow \\
\hline
\end{tabular}

\begin{tabular}{|l|l|l|l|l|}
\hline e- pó & ba & $\beta$ & ó & imbyéngi \\
\hline palaver & AGR & break & FV & Me \\
\hline \multicolumn{4}{|c|}{ The palaver discussion will be held tomorrow } \\
\hline
\end{tabular}

What distinguishes examples (7) from examples (6) is the kind of agreement prefix is attached to the finite verbs. In fact, the prefix ba-, once being preceded by a DP that is semantically a Theme or a Patient, denotes impersonal pronouns like 'they, people' subsuming that the agent is not known. As such, the prefix ba- has nothing to do with its plurality property, but rather stand for no agent passive construction.

Comparing the argument put forward regarding the predicates in (6), we can draw the conclusion that these verbs are not unaccusatives because their arguments cannot be reduced as in (5) or (7). The reason supporting this argument lies on the morphology together with the argument structure of these predicates which cannot allow this.

\subsection{Resultative Construction}

The second test for Embosi unaccusatives is resultative construction. Here are the data:

(8)

\begin{tabular}{|c|c|c|c|c|c|}
\hline a- $\quad W a$ & $\mathrm{a}$ & sing & $\mathrm{i}$ & asaani & tsćtsé \\
\hline Him/her & AGR & wash & $\mathrm{FV}$ & plates & clean \\
\hline
\end{tabular}

\begin{tabular}{|l|l|l|l|l|}
\hline b- misi & a & bèćng & i & tsı̀ \\
\hline Eyes & AGR & turn red & FV & red \\
\hline \multicolumn{4}{|l}{ The eyes turn red } \\
\hline
\end{tabular}

\begin{tabular}{|l|l|l|l|}
\hline c- manyi & a & ßind & i \\
\hline water & AGR & black & FV \\
\hline \multicolumn{2}{|l}{} \\
\hline
\end{tabular}

\begin{tabular}{|l|l|l|l|}
\hline d- etongo & é & wom & i \\
\hline Pool & AGR & dry & FV \\
\hline The pool dried
\end{tabular}

\begin{tabular}{|l|l|l|l|}
\hline e- $\quad$ okandé & o & pumb & ú \\
\hline trouser & AGR & turn white & FV \\
\hline The trouser turns white \\
\hline
\end{tabular}

It appears that the predicates in (8) examples highlight the change of state of the external argument. As things stand, in (8a), we have a true case of resultative construction since the adjective 'tsćtsć' is the result of the predicate 'isinga'. Putting things quite in the same way, it is the fact of washing dishes that makes them clean. Analyzing resultative construction in English, Villa (2014:16) writes: "According to Simpson (1983a), in a resultative construction, the resultative adjective must be predicated of a D-Structure object. In English, resultative adjectives are resultative on the object of a transitive sentence". This argument fits in with Embosi language where the adjective is referring to the object of the predicate.

\subsection{Causative Alternation}

(9)

\begin{tabular}{|l|l|l|l|l|}
\hline a- Kanga & a & kum & u & ndai \\
\hline Kanga & AGR & open & FV & house \\
\hline Kanga opened the house
\end{tabular}




\section{Yvon Pierre Ndongo Ibara}

\begin{tabular}{|l|l|l|l|l|l|}
\hline b- Ndai & e & kum & u & n & u \\
\hline House & AGR & open & & REC & FV \\
\hline The house opened
\end{tabular}

\begin{tabular}{|l|l|l|l|l|l|}
\hline c- Ikia & a & tsamis & i & bea & \\
\hline Ikia & AGR & scatter & FV & things & \\
\hline Ikia scattered things
\end{tabular}

\begin{tabular}{|l|l|l|l|l|l|}
\hline d- Bea & i & tsam & i & n & i \\
\hline Things & AGR & scatter & & REC & FV \\
\hline Things scattered
\end{tabular}

\begin{tabular}{|l|l|l|l|l|}
\hline e- aburu & a & dzoos & i & mboa \\
\hline Foreigners & AGR & spoil & FV & country \\
\hline \multicolumn{4}{|l|}{} \\
\hline
\end{tabular}

\begin{tabular}{|l|l|l|l|l|}
\hline f- mboa & e & dzoo & n & i \\
\hline Country & AGR & spoil & REC & FV \\
\hline The country & \\
\hline
\end{tabular}

The examples in (9) illustrate a case intimacy between transitive and intransitive predicate. This proves that one verb category can semantically instances two different syntactic constructions. In the words of Zwakele (op.cit:44-45)

- This lexical semantic representation is a bi-event structure. This means, the verb .... represents two events and hence two clauses; the first event states the act of causing and the second event expresses the change of state.

In this respect, in (9a) for instance the DP causer, Kanga acts to the extent that the DP object, house is opened. Yet, in (9b) the cause is omitted, hence the DP object appears as the subject showing the state in which the house is. At morphological level, we observe that there is an extensional morpheme -nwhich appears when the causer DP is omitted, that is, when the transitive predicate is used intransitively. This extensional morpheme denotes reciprocity. This illustrates a case of language idiosyncrasy property on a semantic aspect of predicate. If in English reciprocity is semantically because we cannot sometimes be able to capture itmorpho-syntactically as in 'Joyce melt the ice' and 'the ice melt', in French on the contrary we can observe the process as in 'Joyce ouvre la porte' and 'la porte s'ouvre' where the morpheme ' $\mathrm{s}(\mathrm{e})$ ' indicates reciprocity. In Embosi, the reciprocal morpheme and the verb stem final consonant illustrate a case of consonant alternation.

Henry (1995) when dealing the English spoken in Belfast assumes that unaccusative predicates can allow the movement of the verb from the head of the VP to the head of a light. We repeat Henry's examples taken from Radford (2009:251) as follows:

- Leave you now!

- Arrive you before 6 o'clock!

- Be going you out of the door when he arrives!

In Embosi, not only intransitives but also transitive verbs allow this verb movement as shown in (10) examples below.

(10)

\begin{tabular}{|l|l|l|l|l|l|}
\hline a- yaa & la & no & oboso & ma & miti \\
\hline Arrive & for & you & In front & of & midday \\
\hline \multicolumn{7}{|l|}{} \\
\hline
\end{tabular}

\begin{tabular}{|l|l|l|l|l|}
\hline b- dza & no & bea & bi & pé \\
\hline Eat & you & food & this & there \\
\hline \multicolumn{4}{|c|}{} \\
\hline
\end{tabular}




\begin{tabular}{|l|l|l|l|l|}
\hline \hline c- tanga & no & buku & bu & pé \\
\hline Read & you & book & this & there \\
\hline \multicolumn{4}{|l|}{ Read you that book! } \\
\hline
\end{tabular}

The examples in (10) show that Embosi language allows postverbal imperative subjects with intransitive (10a) and transitive predicates $(10 \mathrm{~b}, 10 \mathrm{c})$. As a matter of fact, we cannot posit postverbal imperative subject as a test for unaccusative in Embosi since this movement is attested with other kinds of predicates.

\section{Conclusion}

My article has dealt with unaccusative predicates in Embosi. It appears that unaccusative tests are sensitive to language regarding the morphological productivity. As unaccusativity is a predicate issue, the semantic information encoded in the predicate has different expression cross linguistically. Despite a long list of tests of unaccusativity, it comes out that passivization, resultative construction and causative alternation can be viewed as canonical tests cross linguistically. What basically characterizes unaccusativity is the non agentivity and telicity. Zwakele (op.cit:106) raises a question in his dissertation as follows:

- Another possible suggestion for further research would be to investigate whether a property of unaccusativity in siSwati, is determined by verbs alone or the VP. In some languages, for instance in Dutch and Italian, verbs of motion such as walk, fly, go, etc. become unaccusative when combined with a PP denoting the end point of a physical activity.

Based on example (9) we put forward the hypothesis that the inherent property of the unaccusative predicate depends solely on the verb, not the verb phrase, because the finite form of the verb captures all semantically encoded information.

\section{REFERENCES}

[1] Baker, M. 1988, Incorporation: A Theory of Grammatical Function Changing. Chicago: University of Chicago Press

[2] Belletti, A. and L. Rizzi, 1981, The syntax of ne. Linguistic Review 1, 117-154

[3] Burzio, L. 1986, Italian Syntax: A Government and Binding Approach, Dordrecht: Reidel.

[4] Chomsky, Noam, 1986a, Knowledge of Language: Its Nature, Origin and Use, Praeger, New York.

[5] Chomsky, Noam,1999, Derivation by Phase, MIT Occasional Papers in Linguistics, 18 (also publishedin M. Kenstowicz (ed.), 2001, Ken Hale: A Life in Language, MIT Press, Cambridge, MA, p. 1-52.

[6] Grewendorf, G. 1989, Ergativity in German. Dordrecht :Foris publications

[7] Hall, B. 1965, Subject and Object in English. Dissertation (Ph. D). Massachusetts Institute of Technology.

[8] Harves, S. 2002, Unaccusative syntax in Russian. Dissertation (Ph. D). Princeton University.

[9] Henry, A. 1995, Belfast English and Standard English: Dialect Variation and Parameter Setting, Oxford University Press.

[10] Huang, C. T. J. 1982, Logical Relations in Chinese and the Theory of Grammar, PhD dissertation, MIT.

[11] Levin, B. and M. Rappaport Hovav, 1995, Unaccusativity: at the syntax-lexical semantics interface. Cambridge: MIT Press.

[12] Levin, Beth, 1993, English Verb Classes and Alternations. Chicago: University of Chicago Press.

[13] Perlmutter, D. 1978, Impersonal passives and the Unaccusative Hypothesis. In: 1. Jaeger et al. (eds) Proceedings of the Fourth Annual Meeting of the Berkeley Linguistic Society 4. Berkeley University of California.

[14] Radford, Andrew, 2009, Analysing English Sentences: A Minimalist Approach. Cambridge: CUP

[15] Simpson, Jane, 1983, 'Resultatives'. Papers in Lexical Functional Grammar. eds. L. Levin, M. Rappaport, and A. Zaenen. 143-157. Bloomington, IN: Indiana University Linguistics Club. 
[16] Tallerman, Maggie, 2011, Understanding Syntax, London: Arnold.

[17] Tina M. Villa, 2014, Split-Intransitivity in Swahili and Hittite: An Optimality-Theoretic Perspective. $\mathrm{PhD}$, Louisiana State University.

[18] Van Valin, R. 1990, Semantic Parameters of Split Intransitivity. Language 66:221-60.

[19] Zwakele Nonduduzo Tina Motsa, 2006, Unaccusativity in Siswati, MA Thesis, University of Kwazulu Natal, Durban.

\section{AUTHOR's BIOGRAPHY}

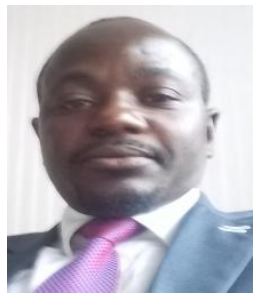

Prof Yvon Pierre Ndongo Ibara, is an Associate Professor in linguistics at Marien N'Gouabi University, Brazzaville (Congo). Former head of Modern Foreign Languages Department at the Faculty of Social Sciences and Humanities and current director Confucius Institute, Prof Ndongo Ibara's research fields concern theoretical linguistics based on Chomskyan generative framework and English language teaching. Apart from English Embosi dictionary (2012), Prof Ndongo Ibara has published more twenty-five articles. 